\title{
Electrocardiographic Findings in Mexican Chagasic Subjects Living in High and Low Endemic Regions of Trypanosoma cruzi Infection
}

\author{
Francisca Sosa-Jurado*, Miguel Mazariego-Aranda**, Nidia Hernández-Becerril, \\ Verónica Garza- Murillo, Manuel Cárdenas, Pedro A Reyes, Kenji Hirayama***, \\ Victor M Monteón/ ${ }^{+}$
}

\begin{abstract}
Instituto Nacional Cardiología “I. Chávez", Juan Badiano 1, Col Sección XVI, México DF 14080 *Hospital de Especialidades Centro Médico Nacional "Manuel Ávila Camacho" IMSS, Puebla, México **Facultad de Ciencias Químicas, Campus IV,

Tapachula Chiapas, México ***Institute of Tropical Medicine, Nagasaki University, Japan
\end{abstract}

In México the first human chronic chagasic case was recognized in 1940. In spite of an increasing number of cases detected since that time, Chagas disease in México has been poorly documented. In the present work we studied 617 volunteers subjects living in high and low endemic regions of Trypanosoma cruzi infection with seroprevalence of $22 \%$ and $4 \%$ respectively. Hemoculture performed in those seropositive subjects failed to demonstrate circulating parasites, however polymerase chain reaction identified up to $60 \%$ of them as positives. A higher level of anti-T. cruzi antibodies was observed in seropositive residents in high endemic region, in spite of similar parasite persistence $(p<0.05)$. On standard 12 leads electrocardiogram (ECG) 20\% to $22 \%$ seropositive individuals from either region showed right bundle branch block or ventricular extrasystoles which were more prevalent in seropositive than in seronegative individuals $(p<0.05)$. In conclusion, the frequency or type of ECG abnormality was influenced by serologic status but not by endemicity or parasite persistence. Furthermore, Mexican indeterminate patients have a similar ECG pattern to those reported in South America.

Key words: Chagas disease - Trypanosoma cruzi - electrocardiogram alterations - seroprevalence - polymerase chain reaction

Chagas disease is an important public health disorder in Latin America. This infectious disease is caused by Trypanosoma cruzi and transmitted by Triatominae insects in most cases.

Data from the World Health Organization state that approximately 90 million people in Latin American countries are exposed to this infection (WHO 1991).

México has an ample array of Triatominae insects, 31 species have been recognized, and it has been found that most of them are naturally infected with $T$. cruzi (Zarate \& Zarate 1980, 1985, Vidal-Acosta et al. 2000).

Epidemiological surveys carried out in different regions of the country have revealed an heterogeneous distribution of the infection (Tay et al. 1980, Salazar et al. 1988, Velasco-Castrejón 1992). Endemic zones have been identified mainly in the coastal and southern regions of México with high seropositivity in rural villages, as well as cases of chronic heart disease (Ruegsegger et al. 1993, Mendoza et al. 1995, Zavála-Castro et al. 1995 Monteón et al. 1996, Hernández-Becerril et al. 2001, Mazariego-Aranda

Research supported by a grant from Instituto Nacional Cardiología I. Chávez (México), a grant-in-Aid for Scientific Research on International Cooperation from Ministry of Education, Science and Culture, Japan (12376001), and a grant from the Japan-US Cooperative Medical Science Program (19992002).

${ }^{+}$Corresponding author. Fax: +52-5573.0994. E-mail: victormonteon@hotmail.com

Received 12 February 2003

Accepted 18 June 2003 et al. 2001). More recently moderate to low seropositivity has been reported in the central part of México (PérezFuente et al. 1998, Rangel-Flores et al. 2001).

The outcome of the disease and progression from indeterminate form of chronic phase to symptomatic in infected people is not completely understood. It has been suggested that several of the role playing factors are: genetic host background, parasite strain, and reinfection (Mendoza et al. 1995, Zavála-Castro et al. 1995, Montamant et al. 1996, Fernández-Mestre et al. 1998, Bustamante et al. 2002).

Chagas disease in México has not been fully documented and scarce reports exist on the indeterminate form of chronic phase. To study this indeterminate chronic phase is an important step towards the systematic study of the disease. In the present work we studied volunteers subjects from two communities with high and low seroprevalence for $T$. cruzi infection.

\section{MATERIALS AND METHODS}

Study area - The study was done in nine rural villages (municipality Palmar de Bravo) located in the highlands, central part of México, Puebla state (2 150-2 $500 \mathrm{~m}$ above sea level), range of temperature from $10^{\circ} \mathrm{C}$ to $26^{\circ} \mathrm{C}$ with 7200 inhabitants, the second area encompasses three communities in the lowlands, located in the southern part of México, Chiapas state ( $600 \mathrm{~m}$ above sea level), range of temperature $23^{\circ} \mathrm{C}$ to $35^{\circ} \mathrm{C}$, with 1500 inhabitants (Fig. 1)

Studied population - In Puebla state, 390 volunteers (Palmar de Bravo municipality) ranging from 15 to 65 years old participated in the study, the mean age was $36.6 \pm 12.3$ years old, and $93 \%$ were female. The excessive proportion of female individuals and poor participation responded to 


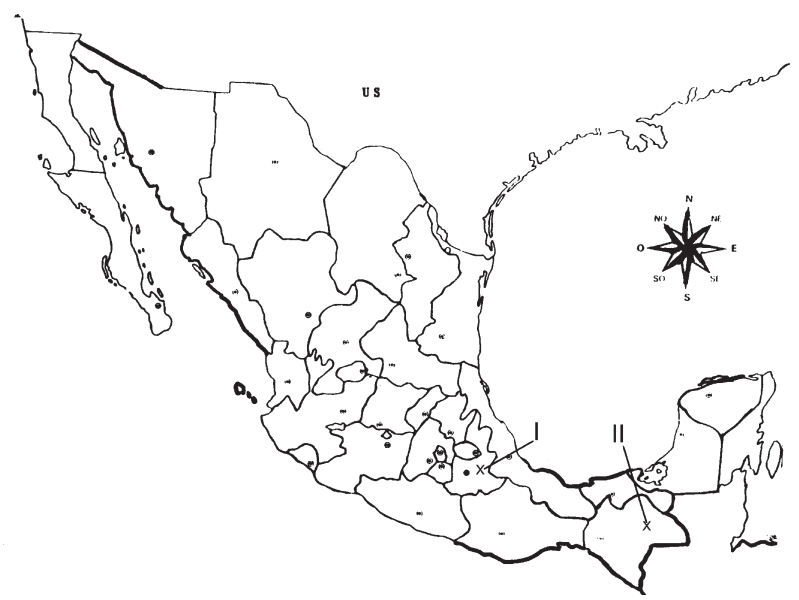

Fig. 1: geographical situation of regions studied. I: high lands (Palmar de Bravo, Puebla state); II: low lands (Lacandon forest, Chiapas state)

cultural behavior, in general male individuals refused to participate in this survey.

In Chiapas state, 227 volunteers from the Lacandon Rainforest ranging from 6 to 73 years old participated in the study, the mean age was $25 \pm 18.6$, and $63 \%$ were females. In this area it was possible to enroll children from local elementary school, obviously under parents approval.

Serology for anti- T. cruzi antibodies, hemoculture, polymerase chain reaction (PCR) specific for T. cruzi was performed in all participants. Electrocardiograms (ECGs) were performed in seropositives volunteers and age matched seronegatives in both areas.

Ethical considerations - This work was done in accordance to "Reglamento de la Ley General de Salud en Materia de Investigación" which stated forearm venipucture as a minimal risk procedure and requires oral consent when illiterate participants are invited to a clinical or epidemiological study. When feasible a written informed consent letter was used. The Ethics Committee of the Institute (Instituto Nacional Cardiología "I. Chávez") approved the study protocol.

Serological test - Indirect immunofluorescence (IIF) detected total IgG anti- T.cruzi antibodies and enzyme linked immunosorbent assay (ELISA) as described previously with minor modifications. In brief, IIF was performed on T. cruzi epimastigote phase, fixed on a microscope slide. Human serum was diluted 1:32 and fluorescein conjugated goat anti-human IgG was used at 1:100 dilution. Positive and negative controls were always included, and the slide was read under epifluorescence microscope (Hernández-Becerril et al. 2001).

ELISA was done using polystyrene plates coated with $10 \mu \mathrm{g} / \mathrm{ml}$ of protein of T. cruzi (Ninoa Mexican strain) extract in alkaline-buffered solution. Human serum was diluted at 1:200 and anti-human IgG-peroxidase conjugate was used at 1:15000 dilution. The reaction was revealed by addition of O-phenilen-diamine and read at $490 \mathrm{~nm}$ in automatic ELISA reader (Hernández-Becerril et al. 2001).

Cut off value was set as follows: sera from 30 healthy seronegative people were pooled and individually tested. Mean OD ratios obtained between individual negative sample and pooled negative sample was analyzed for their distribution. The mean OD ratio of seronegative healthy individuals plus $3 \mathrm{SD}$ was fixed to set the cut off. All healthy individuals had values classified as negative.

$E C G$ - In all participants a standard 12 leads ECG was recorded at a paper speed of $25 \mathrm{~mm} / \mathrm{s}$ with a portable Fukuda Denshi Model FX-2111 electrocardiograph (Fukuda Co.). The tracing was blind analyzed independently by two cardiologists. The criteria for the ECG interpretation were those utilized by the Department of Electrocardiography and Electrophysiology of the Instituto Nacional de Cardiología based on the deductive method of ECG interpretation (De Michelli 1993).

Special attention was given to the presence of arrythmias, A-V heart block, bundle branch blocks (HBBB), fascicular blocks (Cárdenas 1976), atrial and ventricular hypertrophy (Sodi-Pallareset al. 1964), and repolarization abnormalities with change in the ventricular gradient (Cabrera 1958).

Hemoculture - We followed the technique previously described (Luz et al. 1994) with an adjustment. Fifteen milliliters of heparinized blood was spun down at $4000 \mathrm{~g}$ for $10 \mathrm{~min}$ at $4^{\circ} \mathrm{C}$. Plasma was removed and sedimented cells were washed with liver infusion tryptose mediun (LIT) and spun again. The supernatant was removed and settled cells were dived into four tubes with equal amount of LIT supplemented with $10 \%$ of fetal calf serum and incubated at $28^{\circ} \mathrm{C}$ for four months. Monthly evaluation of cultures was performed taking out 10-20 $\mu \mathrm{l}$ aliquots from each tube and observing it under light microscope (400X).

PCR for T. cruzi detection - From 1 to $2 \mathrm{ml}$ of blood sample from each individuals DNA extraction was performed as previously reported (Monteón-Padilla et al. 1999). Lysis buffer was added to each sample (SDS final concentration of $1 \%$ and proteinase $\mathrm{K}$ at $0.2 \mathrm{mg} / \mathrm{ml}$ ). The mixture was incubated for $3 \mathrm{~h}$ at $42^{\circ} \mathrm{C}$ and extracted twice with phenol/cloroform. Subsequently, sodium acetate (final concentration $0.3 \mathrm{M}$ ) and ethanol $95 \%$ added for DNA precipitation. DNA pellet was resuspended in $20 \mu \mathrm{l}$ of sterile water.

Amplification reaction was performed in $50 \mu \mathrm{l}$ volume containing DNA sample $(1 \mu \mathrm{l}), 300 \mathrm{ng}$ of minicircle specific primers KNS1 and KNS2, $0.2 \mathrm{M}$ of each nucleotide, with $2.5 \mathrm{U}$ of Taq polymerase. The reaction was subject to 35 cycles, each cycle $94^{\circ} \mathrm{C}$ for $1 \mathrm{~min}, 56^{\circ} \mathrm{C}$ for $1 \mathrm{~min}$, and $72^{\circ} \mathrm{C}$ for $1 \mathrm{~min}$. The amplified product was run in $2 \%$ agarose, ethidium bromide stained, and visualized under UV illumination. Positive and negative controls were always included for each run. The sensitivity detection of the assay is $0.25 \mathrm{fg}$ of total T. cruzi DNA (Monteón et al. 1994).

Statistical analysis - The descriptive section included mean and standard deviation. The inferential section was supported by the Mann-Whitney test and Chi-square using GraphPad Prism ${ }^{\text {tm }}$ version 2.0.

\section{RESULTS}

From 390 volunteers studied in the highland (Puebla state), located between 2150 to $2500 \mathrm{~m}$ above sea level, 
15 were seropositives by two serological test (4\%). People from these communities are in general poor and malnourish. Houses are made of wood or occasionally brick. The vector recognized was Triatoma barberi. Hemoculture performed in those seropositive subjects failed to demonstrate circulating parasites, but PCR disclosed $60 \%$ of them as T. cruzi DNA carriers (Table I, Fig. 2).

People lived in the lowland (Chiapas state), in the Lacandon Rainforest with a very precarious housing condition; up to $73 \%$ of their houses are made of palms leaves or other natural materials. The bug's eggs are easily carried on this material and the vector becomes domiciliated. The vector recognized was Rhodnius prolixus. Seroprevalence was $22 \%$ (50 out 227 volunteers). Hemoculture evidence for circulating T. cruzi was also negative but, again PCR showed $43 \%$ of positive individuals among seropositive population (Table I, Fig. 2).

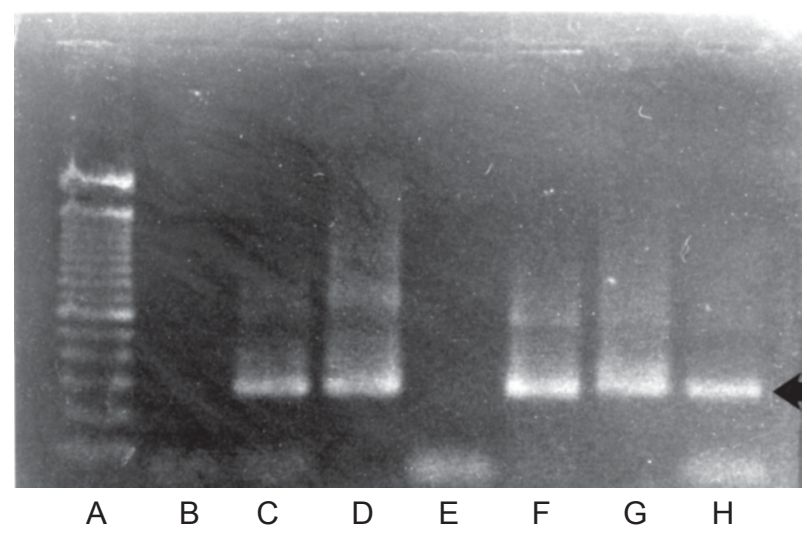

Fig. 2: representative image of polymerase chain reaction products from Trypanosoma cruzi DNA with kinetoplast KNS1 and KNS2 primers. Lanes - A: weight markers; B: negative control (human DNA); C: positive control (T. cruzi DNA); D-H: indeterminate subjects

Level of IgG anti-T. cruzi antibodies between subjects from highlands and lowlands had a clear difference in antibody titer (Fig. 3). Individuals resident in endemic place (lowland: seroprevalence 22\%) showed higher level of anti-T. cruzi antibodies than resident from low endemic region (highlands: seroprevalence 4\%) with statistical significance $p<0.05$ (Mann-Whitney test) but not association between level of antibodies and abnormal ECGs was observed (data not shown).

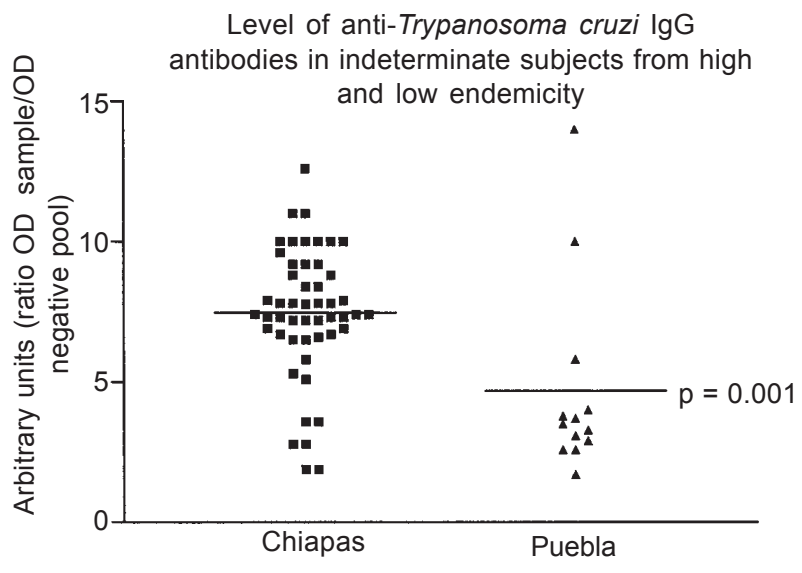

Fig. 3: ELISA test was performed in seropositive subjects from high endemic area (Chiapas $\mathrm{n}=50$ ) and from low endemic (Puebla $\mathrm{n}=$ 15). Arbitrary units = ratio OD sample/OD negative pool (cut off 1.7 arbitrary units)

Ten out of 15 seropositive individuals and 15 seronegative age matched control from the highlands (Puebla state) and 35 out of 50 seropositives and 19 seronegative age matched control from lowlands (Chiapas state) accepted ECG examination.

Only two seropositive subjects from highlands had abnormal ECGs, both with incomplete RBBB. The proportion of seropositive individuals presenting ECG alterations represented $20 \%$ (Table II). One more presented non-specific $\mathrm{T}$ wave changes (data not shown). From the seronegative group none presented BBB (Table II), only one showed prolonged (0-06 mseg) QT segment (data not shown).

In the lowlands eight out of 35 seropositives (22\%) had abnormal ECG, four of them presented incomplete RBBB and two complete RBBB, one showed abnormal left ventricular repolarization, and another one presented arrhytmia (ventricular extrasystole). In the age matched seronegative group only two out $19(11 \%)$ had abnormal ECG with incomplete RBBB (Table II). The association between positive serology and abnormal ECGs was statistically significant in both groups (Chi-square $\mathrm{p}<$ 0.05).

Finally, there was no difference between place of residence and type or frequency of ECGs alterations.

Table III shows that regardless of age of seropositive individuals had no association with abnormal ECG, same frequency of altered ECG was found either young or old people. In the age group between 20 to 40 years old, four

TABLE I

Seroprevalence, parasitemic state, vector and geographic data

\begin{tabular}{|c|c|c|c|c|c|c|}
\hline Rural communities & $\begin{array}{l}\text { Anti-T.cruzi } \\
\text { prevalence }\end{array}$ & $\begin{array}{l}\text { Paras } \\
\text { Hem }\end{array}$ & $\begin{array}{l}\text { emia } \\
\text { PCR }\end{array}$ & Main vector & $\begin{array}{c}\text { Annual } \\
\text { temperature }\left({ }^{\circ} \mathrm{C}\right)\end{array}$ & $\begin{array}{l}\text { Sea level } \\
(\mathrm{m})\end{array}$ \\
\hline Puebla $n=390$ (highland) & $4 \%$ & None & $60 \%$ & Ttiatoma barberi & $10-25$ & $2150-2500$ \\
\hline Chiapas $n=227$ (lowland) & $22 \%$ & None & $43 \%$ & Rhodnius prolixus & $23-35$ & 600 \\
\hline
\end{tabular}

Anti-Trypanosoma cruzi antibodies were detected by ELISA and IIF test. PCR test was applied to seropositive subjects using primer KNS1 and KNS2 derived from kinetoplast minicircle. Hemoculture performed as described in Material and Methods. 
TABLE II

Electrocardiogram (ECG) findings in seropositive and seronegative subjects

\begin{tabular}{lcc}
\hline \multirow{2}{*}{ Community } & \multicolumn{2}{c}{ Abnormal ECG $^{c}$} \\
\cline { 2 - 3 } & Seropositive & Seronegative \\
\hline Puebla $^{a}$ (highland) & $2 / 10(20 \%)$ & $0 / 15(0 \%)$ \\
Chiapas $^{b}$ (lowland) & $8 / 35(22 \%)$ & $2 / 19(10 \%)$ \\
Total $^{d} \mathrm{p}<0.05$ & $10 / 45(22 \%)$ & $2 / 34(6 \%)$ \\
\hline
\end{tabular}

$a$ : ECG was performed in 10 out of 15 seropositive and 15 seronegative subjects; $b$ : ECG was performed in 35 out of 50 seropositive and 19 seronegative subjects; $c$ : the main ECG alterations were right bundle-branch blockage (8), ventricule extrasystole (1) and altered repolarization (1); $d$ : Chi-square test. Comparing seropositives vs seronegatives from both regions.

TABLE III

Range of age, mean age of indeterminates subjects with normal or altered electrocardiogram (ECG)

\begin{tabular}{cc}
\hline $\begin{array}{c}\text { Age range of seropositive } \\
\text { subjects (years) }\end{array}$ & Abnormal ECG \\
\hline $20<40(\mathrm{n}=20)$ & $4(21 \%)$ \\
$\geq 40(\mathrm{n}=25)$ & $6(26 \%)$ \\
Mean age of seropositives with & $42 \pm 12.2$ \\
abnormal ECG $(\mathrm{n}=10)$ & (years old) \\
Mean age of seropositives with & $41 \pm 15.7$ \\
normal ECG $(\mathrm{n}=35)$ & (years old) \\
\hline
\end{tabular}

All 45 seropositive individuals are from both Mexican regions.

out of 19 seropositive individuals had abnormal ECGs, representing $21 \%$ and for seropositive individuals above 40 years old a discrete increase was observed: six out of 23 , representing $26 \%$, without any statistical significance. The same was true when compared mean age of seropositives with normal or abnormal ECG.

\section{DISCUSSION}

The results of this study extends and corroborates the heterogeneous distribution of T. cruzi infection in México (Salazar et al. 1988, Velasco-Castrejón et al. 1992, Ruegsegger et al. 1993, Mendoza et al. 1995, Zavála-Casrtro et al. 1995, Mazariego-Aranda et al. 2001, Rangel-Flores et al. 200), linked to geographic differences, housing conditions, as well as the kind of vector.

In this study higher seroprevalence was observed in the Lacandon Rainforest housing and the presence of an aggressive vector ( $R$. prolixus), in addition to ignorance triatomine-borne infectious and no vector control, enhanced transmission and potential risk to reinfection. Unfortunately trypanosomiasis is not yet considered as priority in the Mexican Health Programs. This is the reason why transmission continues high in some areas of México.

Although both studied regions share several risk factors, including similar malnourish prevalence, in the highland the vector was different (T. barberi) and localized outside of living houses. Unfortunately cultural patterns of inhabitants did not allow to measure infestation index in order to compare them, in addition to the poor interest to participate in this survey.
Detection of circulating parasite is the best proof of infection. This is a difficult task in the chronic phase. We applied hemoculture technique to search for circulating T. cruzi with negative results due to small amount of blood was used to performed it as volunteers refused to give more than $15 \mathrm{ml}$ of blood, even though parasitemia was revealed by PCR in $43 \%$ and $60 \%$ of seropositive individuals from high and low endemic place respectively.

Indicating a very low parasite-circulating load in these chronic infected subjects. Despite, differences in infection rate between high and low endemic regions, parasitemia detected by PCR was comparable for both groups (Table I).

In our study we found that people living in high endemic areas for T. cruzi infection, showed higher antiT. cruzi antibodies than people from low endemic areas $(\mathrm{p}<0.05)$. This finding may suggests that reinfection could take place in high endemic region enhancing high level of specific antibodies. Although, in human beings it is difficult to prove that reinoculation is taking place, an animal model has been tested and measured indirectly by the antibody levels, showing that during the chronic phase higher anti-T. cruzi antibody levels is presented in reinfected dogs than in those infected only once $(\mathrm{p}<$ 0.05) (Machado et al. 2001). Then, high anti-T. cruzi antibodies level in people from endemic areas may be a reflex of reinfection besides parasite persistence that is because by PCR, it was possible to amplified parasite DNA in both people from high and low endemic regions.

It is also known that chronic chagasic cardiomyopathy patients display high anti-T. cruzi antibodies even in those infected cases that lived in endemic zones for only short time of their life (Cerban et al. 1993, Umezawa et al. 1996, Hernández-Becerril et al. 2001). This conflicting point deserves further analysis to explain why antibody levels could be different between resident from high and low endemic regions in spite of parasite persistence in both groups.

In regard to ECG changes, we found mainly conduction defects such as RBBB, the most prevalent finding in seropositive individuals, four times more frequent than among seronegative ones, with statistical significance ( $p$ $<0.05$ ). Non-specific T wave and S-T segment changes were found in some cases without correlation with seropositivity. No other ECG changes were recorded

Although, nonspecific ECG abnormalities have been previously reported in healthy population, the most prevalent are non-specific $\mathrm{T}$ wave and $\mathrm{S}-\mathrm{T}$ segment represent 8.6 subjects per 1000 , RBBB 1.6 per 1000 and LBBB 0.2 per 1000 (Averill \& Lamb 1960). In contrast, among seropositive subjects correlation between abnormal ECG tracings and positivity for T. cruzi was found.

The prevalence rate of abnormal ECGs in seropositive subjects was not influenced by either region or rate of infection or reinfection. In both low-endemic and high endemic regions, abnormal ECG tracing was around 20\% in the seropositive population. Although, it has been suggested that reinfection may play a role in the evolution of Chagas disease (Avila et al. 1987), in our data, we found the same frequency of ECGs alteration for both groups from low and high endemic areas. 
Previous longitudinal studies carried out in the chronic phase in Brazilian individuals have shown electrocardiographic changes ranging from $23 \%$ to $38 \%$ during long-term follow-up (Dias 1985, Coura et al. 1985). While in a transversal study carried out in two different geographic areas in Ecuador abnormal ECG findings in seropositive subjects was between $15 \%$ to $40 \%$ (Kawabata et al. 1987). Present results showed ECGs abnormalities in up to $22 \%$ in the seropositive individuals from either high or low endemic areas.

This data coincides with that reported in South American literature. However, it has to be emphasized that ECG abnormalities taken into account in this work were only those compatible with rhythm and conduction defects a recognized early feature for heart involvement in chronically infected chagasic people. Although, statistical significance was obtained for seropositive subjects with ECG alterations, definitive conduction defect associated with positive serology was present only in $16 \%$ of them. Similar low percentage was also reported in a recently published paper studying Brazilian chronic infected subjects, those who developed conduction defects like RBBB, LBBB, atriventricular blockage, or all of them (Ianni et al. 2001). In general, the indeterminate form of Chagas disease recognized in our population is similar to those reported in South America.

Subtle changes have been detected in Brazilian patients using nuclear angiographies, cardiac catheterization and even endomyocardial biopsy (Mady \& Galoano 1979, Pereira-Barreto et al. 1986, Marin-Neto et al. 1988), these are invasive procedures which are ethically questionable because these alterations are generally not intense enough to lead to deterioration of myocardial function, furthermore they are not generally available in field studies. Non invasive techniques such as echocardiography represent a versatile method in the evaluation of the heart, and it has a good correlation with invasive methods in the determination of ejection fraction. Evaluation of indeterminate chagasic patients by echocardiography and its variant, the so called Doppler Tissue Imaging showed right ventricular functional changes statistically different from a comparison population (Lins et al. 2002).

Although no inference is acceptable in regards to our observations, and echocardiography was not available for us in this field study, the presence of abnormal conduction of the heart electric impulse detectable by ECG in a fifth of tested people, points out that non overt clinical heart disease does exist and may be a progressive condition develops in susceptible cases. Now it is necessary to carry out long-term-follow-up studies to support these preliminary findings.

In conclusion the present work shows a significant occurrence of human Chagas disease in some parts of México, affecting the general population and producing heart lesions detectable by ECG. The rate of abnormal ECGs in seropositives was not influenced by the grade of endemic, however anti-T. cruzi antibody levels was higher in people living in high endemic than in low endemic zone in spite of parasite persistence in both. Vector control actions and medical care to infected individuals should be encouraged in such areas.

\section{ACKNOWLEDGMENTS}

To Silvia Monteón for carefully reading of the manuscript.

\section{REFERENCES}

Averill K, Lamb L 1960. Electrocardiographic findings in 67375 asymptomatic subjetcs. Am J Cardiol 6: 76-83.

Avila H, Beloscar J, Bottasso O, Morini J 1987. Alteraciones electrocardiográficas en individuos infectados con Trypanosoma cruzi con distintos tiempos de residencia en áreas de alta endimicidad. Medicina (Buenos Aires) 47: 154-158.

Bustamante J, Rivarola H, Fernández A, Enders J, Fretes R, Palma J, Paglini-Oliva P 2002. Trypanosoma cruzi reinfections in mice determine the severty of cardiac damage. Int J Parasitol 32: 889-896.

Cabrera E 1958. Teoría y Práctica de la Electrocardiografía, La Prensa Médica Mexicana, México, p. 10-47.

Cárdenas M 1976. La Clínica de las Arrítmias, La Prensa Médica Mexicana, México, p. 50-72.

Cerban F, Gae S, Menso E, Vottero-Cima E 1993. Chagas' disease: IgG isotypes against Trypanosoma cruzi cytosol acidic antigens in patients with different degree of heart damage. Clin Immunol Immunopathol 67: 25-30.

Coura JR, Abreu LL, Pereira JB, Willcox HP 1985. Morbidade da doença de Chagas: IV Estudo longitudinal de dez anos em Pains e Iguatama, Minas Gerais, Brasil. Mem Inst Oswaldo Cruz 80: 73-80.

De Michelli A 1993. Trayectoria de la electrocardiografia Mexicana. Arch Inst Cardiol (Mex) 63: 259-266.

Dias JCP 1985. História natural. In JR Cancado, M Chuster (eds), Cardiopatia Chagásica, Fundação Carlos Chagas, Belo Horizonte, p. 99-113.

Fernández-Mestre M, Layrisse Z, Montagnani S 1998. Influence of the HLA class II polymorphism in chronic Chagas' disease. Parasite Immunol 20: 197-203.

Hernández-Becerril N, Nava A, Reyes PA, Monteón VM 2001. IgG suclass reactivity to Trypanosoma cruzi in chronic chagasic patients. Arch Cardiol Mex 71: 199-205.

Ianni BM, Arteaga E, de Carvalho C, Pereira AC, Mady C 2001. Chagas heart disease: evolutive evaluation of electrocardiographic and echocardiographic parameters in patients with the indeterminate form. Arq Bras Cardiol 77: 59-62.

Kawabata M, Uchiyama T, Mimori T, Hashigochi Y, de Coronel V 1987. Association of electrocardiographic abnormalities with seropositivity to Trypanosoma cruzi in Ecuador. Trans R Soc Trop Med Hyg 81: 7-10.

Lins B, Santana-Machado F, Pinho-Ribeiro AL 2002. Detection of early right ventricular dysfuction in Chagas' disease using Doppler Tissue Imaging. JAM Soc Echocardiogr 15: 1197 1201.

Luz Z, Coutinho M, Cançado R, Krettli A 1994. Hemocultura: técnica sensível na detecção do Trypanosoma cruzi en pacientes chagásicos na fase crônica de doença de Chagas. Rev Soc Braz Med Trop 27: 143-151.

Machado E, Fernandes A, Murta S, Vitor R, Camilo D, Pinheiro S, Reis E, Adad S, Romanha A, Pinto-Dias JC 2001. A study of experimental reinfection by Trypanosoma cruzi in dogs. Am J Trop Med Hyg 65: 958-965.

Mady CM, Galoano N 1979. Estudo hemodinâmico na forma indeterminada da doença de Chagas. Arq Bras Cardiol 32(Supl. 1): 155.

Marin-Neto JA, Marzullo P, Souza ACS 1988. Radionuclide evidence for early predominant rigth ventricule involvement in patients with Chagas'disease. Can J Cardiol 4: 231-236.

Mazariego-Arana MA, Monteón VM, Balllinas-Verdugo A, Hernández-Becerril N, Alejandre-Aguilar R, Reyes PA 2001. 
Seroprevalence of human Trypanosoma cruzi infection in different geographic zones of Chiapas, México. Rev Soc Bras Med Trop 34: 453-458.

Mendoza JA, Miranda E, Velasco-Castrejón O, Maciel MO 1995. Cardiopatía chagásica crónica. Presentación de 60 casos. Arch Inst Cardiol (Mex) 65: 546-550.

Montamant E, D'oro G, Gallerano R, Sosa R, Blanco A 1996. Characterization of Trypanosoma cruzi population by zymodemes: correlation with clinical picture. Am J Trop Med Hyg 55: 625-628.

Monteón VM, Negrete C, Reyes PA 1996. Chronic chagasic with parasitemic state (Preliminary Report). Arch Med Res 27: 335-337.

Monteon VM, Reyes PA, Rosales-Encina JL 1994. Detección de Trypanosoma cruzi en muestras experimentales por el método de reacción en cadena de la ADN polimerasa. Arch Inst Cardiol (Mex) 64: 135-143

Monteón-Padilla V, Hernández-Becerril N, Guzmán-Bracho C, Rosales-Encinas J, Reyes-López A 1999. American trypanosomiasis (Chagas's disease) and blood banking in México city: seroprevalence ant its potential transfusional transmission risk. Arch Med Res 30: 393-398.

Pereira Barrueto, Mady C, Arteaga FE 1986. Right ventricular endomyocardial biopsy in chronic Chagas disease. $\mathrm{Am}$ Heart J 111: 307-312.

Pérez-Fuentes R, Sánchez Guillen M, González-Alvarez C, Monteón VM, Reyes PA, Rosales-Encina JL 1998. Humoral nitric oxide levels and antibody immune response of symptomatic and indeterminates Chagas disease patients to commercial and autochthonous Trypanosoma cruzi antigen. Am J Trop Med Hyg 58: 715-720.

Rangel-Flores H, Sánchez B, Mendoza-Duarte J, Bernabé C, Brenieré F, Ramos C, Espinoza B 2001. Serologic and parasitologic demostration of Trypanosoma cruzi infections in an urban area of central México: correlation with electrocardiograpic alterations. Am J Trop Med Hyg 65: 887-895.
Ruegsegger LG, Monteón VM, Marcuschamer J, Reyes PA 1993. Tripanosomiasis americana (enfermedad de Chagas). Encuesta clínica-serológica en un municipio rural oaxaqueño. Arch Inst Cardiol (Mex) 63: 145-148.

Salazar PM, de Haro I, Uribarren T 1988. Chagas disease in México. Parasitol Today 4: 348-351.

Sodi-Pallares D, Biskeni A, Medrano CA 1964. Electrocardiografía y Vectocardiografia Duductivas, La Prensa Médica Mexicana, México, p. 23-52.

Tay J, Salazar PM, Buccio MI 1980. La enfermedad de Chagas en la República Mexicana. Sal Pub (Mex) 22: 409-450.

Umezawa E, Shikanai-Yasuda M, Stolf M 1996. Changes in isotype composition and antigen recognition of antiTrypanosoma cruzi antibodies from acute to chronic Chagas disease. J Clin Lab Analy 10: 407-413.

Velasco-Castrejon O, Valdespino JL, Tapia-Conyer R, Salvatierra E 1992. Seroepidemiología de la enfermedad de Chagas en México. Sal Pub (Mex) 34: 186-196.

Vidal-Acosta V, Ibañez-Bernal S, Martínez-Campos C 2000. Infección natural de chinches Triatominae con Trypanosoma cruzi asociados a la vivienda humana en México. Sal Pub (Mex) 42: 496-503.

WHO-World Health Organization 1991. Control of Chagas, disease. Report of the WHO expert committee. Geneva. WHO Technical Report Series 811: 1-95.

Zarate LG, Zarate RJ 1980. The biology and behaviour of Triatoma barberi (Hemiptera: Reduviidae) in México. I. Blood sources and infection with Trypanosoma cruzi. J Med Entomol 17: 103-116.

Zarate LG, Zarate RJ 1985. A checklist of the Triatominae (Hemiptera: Reduviidae) of México. Int J Entomol 27: 102-127.

Zavála-Castro JE, Gutiérrez-Flota H, Barrera-Pérez MA, BoliSólis J, Zavala-Velázques JE 1995. Cardiopatía chagásica crónica detectada en el Hospital General Regional O'Horan, Mérida, Yucatán, México. Arch Inst Cardiol (Mex) 65: 541545. 